\title{
The agency of digital tools
}

Both analogue and digital drafting tools exert significant influence over how architects imagine. As Paul Emmons has suggested (arq 9:3/4, 227-35), dividers - which were once walked across a page to measure out dimensions - translated the site-based practice of pacing out buildings into the medium of scaled drawing, encouraging architects to understand drawings as surrogate sites. Later, the T-square and parallel motion encouraged rectilinear layouts and axial thinking. Similarly, digital tools have their own agency. SketchUp, for example, works with extrusions and seems to encourage the architectural expression of boxes and frames. The consequences of these tools that architects imagine with, however, and their inherent modes of thinking, remain under-examined.

This issue of arq, curated by Nathalie Bredella and Carolin Höfler, results from a seminar on architecture and digital media held in Berlin in June 2015. It probes the histories and cultures informing the development of digital tools in architecture. Which intellectual traditions have been at work in the development of various tools? Which ideas of culture, technology and architecture have shaped their emergence? As Bredella and Höfler put it, the articles collected here 'address the understanding of architectural design as a historically constructed system of medial, discursive, technical and institutional practices', 'with a focus on the agency of digital tools'. Papers address the connections between these tools and the economic, legal and technological networks where they were made, along with their own digital construction techniques.

Daniel Gethmann investigates Bernard Hafner's ‘Comparative Simulation of Alternative Urban Prototypes' from 1968-71 as an illustration of the emergence of programmatic invention, and coding, out of cybernetics theory (pp. 10-20). Daniela Fabricius, meanwhile, shows how the engineer Frei Otto used physical models alongside digital calculations to develop methods of representation that prefigured digital modelling (pp. 21-32). Jan Müggenburg and Claus Pias address how the methodological appeal of cybernetics has had a lasting effect on architecture (pp. 33-44). Susanne Hauser then addresses slippages between the German term Entwurf and the English word 'Design' to open up a broader discussion about ideas of rationalisation and objectivity (pp. 45-51). 
4 arq $\cdot \operatorname{vol} 21 \cdot \mathrm{no} 1 \cdot 2017 \mid$ leader

The remaining three papers in this arq - unusually - take the form of extended conversations. The first is with Robin Forrest, who collaborated with CAD pioneer Steven A. Coombs in the $1970 \mathrm{~s}$ and was a founding member of the Cambridge CAD group, reflecting on the conceptual rearrangement of design practices around the processing, display, and manufacturing capacities of computers (pp. 53-64). The second is with Robert Aish, former Director of Research at Bentley and Director of Software Development at Autodesk, who considers the evolution of architectural computing from the Building Modelling Systems of the 1980s into ideas of design computation (pp. 65-73). The third conversation is with Reinhold Martin, historian of corporate cultures and technologies of organisation, who considers questions of human subjectivity in relation to computerisation (pp. 74-80).

This issue of arq thus presents a partial history of the agency of digital tools in architecture. It informs a better understanding of how those tools operate in the present, and how their operations might influence what we do, as architects, in the future.

THE EDITORS 